\title{
National Analysis of Sepsis Hospitalizations and Factors Contributing to Sepsis In-Hospital Mortality in Canada
}

Liudmila Husak, Annette Marcuzzi, Jeremy Herring, Eugene Wen, Ling Yin, Dragos Daniel Capan and Geta Cernat

\begin{abstract}
Sepsis is one of the leading causes of in-hospital mortality in Canada. Patient safety is an important component of sepsis prevention and control. The Canadian Institute for Health Information recently released a report that examines a national picture of sepsis hospitalizations and mortality. This article highlights and expands some of the key findings from this report. Specifically, we look here more closely at patients admitted through the emergency departments (ED) in order to determine if earlier recognition of sepsis in the ED would lead to improved patient outcomes.
\end{abstract}

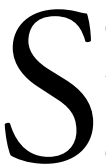
epsis is a leading cause of mortality; at $30-50 \%$, the mortality rate associated with sepsis is markedly high (Surviving Sepsis Campaign 2008). A prospective observational study of 12 Canadian community and teaching hospital critical care units found that mortality for patients with severe sepsis was slightly over 38\% (Martin et al. 2009). Additionally, the personal and economic costs associated with sepsis are high. With more than 18 million cases of severe sepsis worldwide each year, the disease is linked to increased hospital resource use and prolonged stays in intensive care units (ICUs) (Angus et al. 2001; Surviving Sepsis Campaign 2008).

Sepsis is a complex syndrome that is difficult to define. It is also difficult to diagnose because there is no "typical presen- tation"; the signs and symptoms are highly variable. In the medical community, definitions of sepsis have been developed and subsequently rethought due to both advances in the understanding of the condition and the introduction of potential new therapies (Levy et al. 2003; Members of the American College of Chest Physicians et al. 1992).

So, what is sepsis? It is the clinical syndrome defined by the presence of both whole-body infection and a systemic inflammatory response (Levy et al. 2003). When sepsis is complicated by organ dysfunction in at least one body system, it is referred to as severe sepsis. Septic shock occurs when severe sepsis is made worse by a state of acute circulatory failure. It is characterized by persistent arterial hypotension that is unexplained by other causes, and occurs despite adequate volume resuscitation.

A 2009 report by the Canadian Institute for Health Information (CIHI) provides a national picture of sepsis hospitalizations and mortality. This is the first time that the number of sepsis hospitalizations, mortality rate and characteristics of patients with sepsis have been captured for acute care hospitals at the national level. After the report was published, the scope of the sepsis study was expanded to look more closely at patients admitted through the emergency departments (EDs). Patients with sepsis were tracked prior to their admission to hospital in order to determine if earlier recognition of sepsis in the ED would have led to improved patient outcomes. 


\section{Methods}

CIHI's Discharge Abstract Database (DAD) was used to conduct data analyses. Hospitalizations with a discharge date between April 1, 2004, and March 31, 2009, were selected. Due to the differences in data collection, Quebec data were not included.

The unit of analysis was one hospitalization - that is, one episode of care. To account for transfers from one acute hospital to another, individual abstracts were combined to build episodes of care or hospitalizations. A transfer was assumed to have occurred if admission to an acute care institution occurred on the same day or prior to discharge from the preceding acute care institution.

Data on ED visits were extracted from the National Ambulatory Care Reporting System (NACRS) for the period from April 1, 2008, to March 31, 2009. This study was focused on Ontario emergency data from NACRS.

Patients with sepsis or severe sepsis were identified using specific codes from the International Statistical Classification of Diseases and Related Health Problems, 10th Revision, Canada (ICD-10-CA), and the Canadian Classification of Health Interventions (CCI) (see Appendix 1). The number of pre-existing co-morbidities (having impact on patients' treatment and length of stay) was determined using the Charlson Index Score (Quan et al. 2005). The co-morbid conditions coded as type M, 1, W, X and Y (not type 2 on the same abstract) were used to calculate the Charlson Index Score for the first sepsis admission. Patients were considered admitted to an ICU if an ICU stay was recorded in the DAD at any time during the episode of care. Patients were considered directly admitted to an ICU from the ED if the discharge disposition on

\section{Figure 1. Sepsis hospitalization rates, Canada}

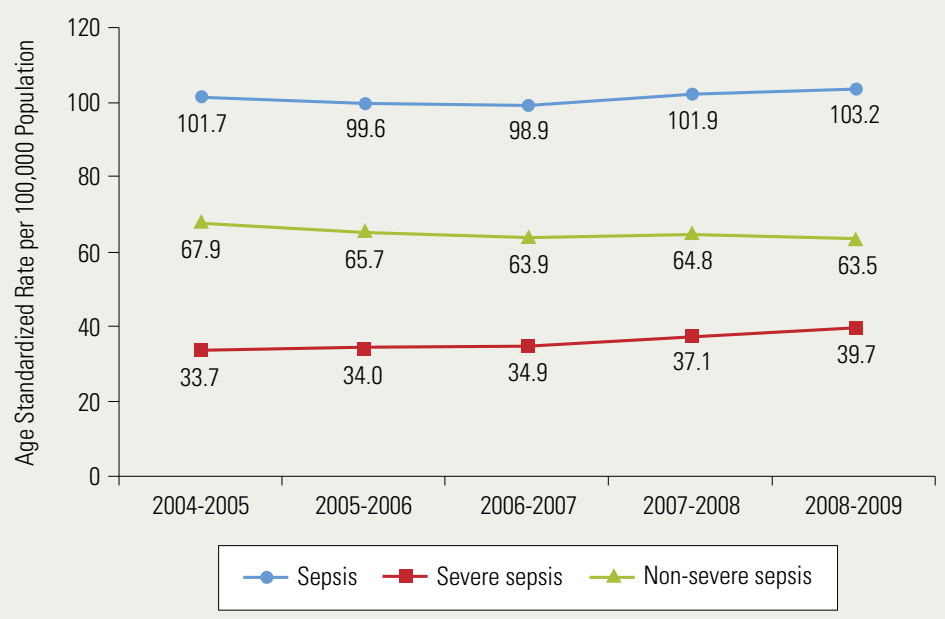

Source: Discharge Abstract Database, Canadian Institute for Health Information. their NACRS record was recorded as 5. Specific criteria based on diagnosis typing were used to determine if sepsis occurred before or after admission to hospital (Canadian Institute for Health Information 2009: 14).

\section{Results \\ Sepsis Hospitalizations and Characteristics of Patients}

In 2008-2009, a total of 30,587 sepsis hospitalizations were observed in Canada (outside Quebec), up from 26,803 hospitalizations in 2004-2005. In 4.0\% of patients, sepsis occurred more than once in a year. Severe sepsis was observed in $39.4 \%$, or 12,063, of all sepsis hospitalizations.

While hospitalization rates for all sepsis remained similar from 2004-2005 to 2008-2009 ( $p=.41)$, hospitalization rates for severe sepsis increased by $17.8 \%(p=.01)$, after population growth and aging were taken into consideration (Figure 1).

Older adults and young children accounted for the majority of sepsis cases. Patients who were 60 and older comprised $60.6 \%$ of all sepsis hospitalizations in 2008-2009. The median age of patients with sepsis was 66. Among patients with sepsis, there were more men than women: $54.6 \%$ of patients were men.

Patients with sepsis tended to have more pre-existing co-morbidities than did patients hospitalized for other reasons (Table 1). At least one pre-existing co-morbidity was recorded in $44.5 \%$ of patients with sepsis, as opposed to $23.1 \%$ of other patients. The most frequent co-morbidities in patients with sepsis were diabetes and cancer.

The majority (79\%) of patients with sepsis were admitted via the EDs, while $12.4 \%$ were admitted directly, $6.6 \%$ were newborns and $2 \%$ came either from clinics or day-surgery centres of the reporting facilities. Most of patients who survived sepsis were discharged home (56.4\%). About 21.1\% of patients with sepsis were discharged to home settings with external support, and $15.8 \%$ went to continuing care facilities.

Among patients with severe sepsis, the majority (62.6\%) had one system affected by organ dysfunction (Table 2 ). The respiratory system was the most commonly affected, followed by the renal and cardiovascular systems.

\section{Sepsis Mortality}

In 2008-2009, 9,320 patients with sepsis died in hospitals across Canada (outside Quebec), which represented $10.9 \%$ of all deaths occurring in hospitals. The crude mortality for all patients with sepsis was 30.5\% in 2008-2009 (45.2\% for patients with severe sepsis and $20.9 \%$ for patients whose sepsis did not progress to severe). 
Table 1. Charlson Index Score, 2008-2009

\begin{tabular}{|l|c|c|}
\hline Charlson Index Score & $\begin{array}{c}\text { Among Patients with } \\
\text { Sepsis (\%) }\end{array}$ & $\begin{array}{c}\text { Among All Other } \\
\text { Hospitalizations (\%) }\end{array}$ \\
\hline 0 & 55.5 & 76.9 \\
\hline 1 or 2 & 30.4 & 18.4 \\
\hline 3 or more & 14.1 & 4.7 \\
\hline
\end{tabular}

Source: Discharge Abstract Database, Canadian Institute for Health Information.

Table 2. Acute organ failure in patients with severe sepsis, 2008-2009

\begin{tabular}{|l|l|l|}
\hline Number of Systems Failing & $\begin{array}{l}\text { Percent } \\
\text { Occurrence }\end{array}$ & Percent Mortality (95\% Cl) \\
\hline 1 & 62.6 & $39.1(38.0-40.2)$ \\
\hline 2 & 27.1 & $52.8(51.1-54.5)$ \\
\hline 3 or more & 10.3 & $62.0(59.3-64.7)$ \\
\hline Organ System* & $\begin{array}{l}\text { Percent } \\
\text { Occurrence }\end{array}$ & Percent Mortality (95\% Cl) \\
\hline Respiratory & 54.5 & $48.3(47.1-49.6)$ \\
\hline Renal & 51.6 & $49.9(48.7-51.1)$ \\
\hline Cardiovascular & 19.8 & $45.8(43.8-47.8)$ \\
\hline Hepatic & 4.9 & $70.0(66.2-73.7)$ \\
\hline Hematological & 9.4 & $51.4(48.5-54.3)$ \\
\hline Central nervous & 9.9 & $44.7(41.9-47.5)$ \\
\hline
\end{tabular}

$\mathrm{Cl}=$ confidence interval.

*Each system was counted independently.

Source: Discharge Abstract Database, Canadian Institute for Health Information.

\section{Hospital Care}

The median total length of hospital stay for patients with sepsis was 12 days in 2008-2009 - approximately nine days longer than the median length of stay due to other reasons (Table 4). Furthermore, patients with severe sepsis stayed in hospital about 11 days longer than patients whose sepsis was not severe.

About $45.1 \%$ of all patients with sepsis and about $57.3 \%$ of patients with sepsis who died had stayed in ICUs (Table 5). The median length of an ICU stay for patients with sepsis in 2008-2009 was 6.3 days - about four days longer than the ICU stay of patients admitted for other reasons. Patients with severe sepsis were 2.6 times more likely to be admitted to the ICU and stayed there about six days longer than patients whose sepsis was not severe.

\section{Early Recognition of Sepsis and Its Effect on Patient Outcomes: An Analysis of Ontario ED Data}

Early recognition and consistent implementation of evidence-based bundles of care have been shown to improve outcomes for patients with sepsis (Levy et al. 2010). In this analysis of Ontario 2008-2009 NACRS data, the existing study cohort was tracked prior to in-hospital sepsis admission. Data on ED visits that occurred on the same day as in-hospital sepsis admission was used to determine if sepsis was recognized in the EDs and how it affected patient outcomes.

A total of 16,152 patients $(52.8 \%$ of the existing sepsis cohort) were treated in Ontario acute care hospitals. Of these, 12,508 (77.4\%) had an ED visit that took place on the same day prior to in-hospital admission. For the majority of patients $(10,173[81.3 \%])$, sepsis was identified as occurring before admission to the hospital. These patients comprised a

Some patients with sepsis were more likely to die than others. Older age, female gender, the presence of pre-admission co-morbidities, severe sepsis and sepsis that occurred after admission to hospital were associated with significantly higher odds of dying in patients with sepsis (Table 3).

There were no significant changes in risk-adjusted sepsis mortality rates over the five years $(p=.11$; Figure 2$)$. Rates were adjusted using a logistic regression model for age, gender, Charlson Index Score and sepsis occurring after admission as covariates. cohort for further analyses as they may have already presented signs and symptoms of sepsis in the ED.

The majority of hospitalized patients with sepsis did not receive a sepsis diagnosis in the ED. Out of the cohort of 10,173 patients identified as having sepsis prior to admission, only 2,688 (26.4\%) had sepsis identified and recorded on their ED chart during their ED visit. For patients where sepsis was not identified on the ED chart, various conditions were listed as main problems (Table 6).

Patients for whom sepsis was identified in the ED experi- 


\section{Figure 2. Risk-adjusted in-hospital mortality rate for all patients with sepsis}

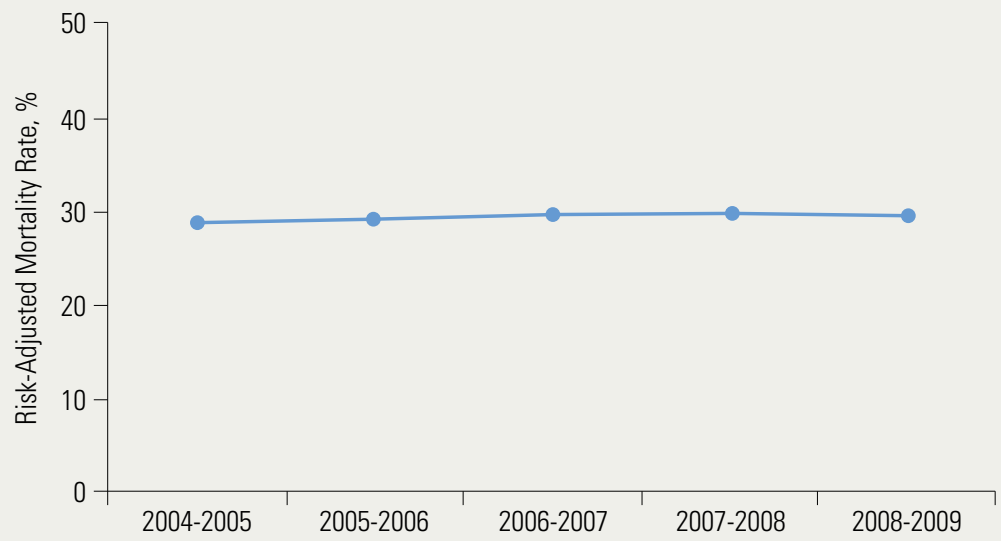

Source: Discharge Abstract Database, Canadian Institute for Health Information

Table 3. Factors affecting sepsis mortality in hospital*

\begin{tabular}{|l|l|l|}
\hline & Odds Ratio & $\mathbf{9 5 \%} \mathbf{~ C I}$ \\
\hline Age (each additional year) & 1.034 & $1.033-1.034$ \\
\hline Women compared with men & 1.08 & $1.05-1.11$ \\
\hline $\begin{array}{l}\text { Charlson Index Score (compared } \\
\text { with no Charlson Index } \\
\text { co-morbidities) }\end{array}$ & 1.38 & $1.34-1.42$ \\
\hline 1 or 2 & 2.28 & $2.20-2.36$ \\
\hline 3 or more & 3.01 & $2.93-3.09$ \\
\hline $\begin{array}{l}\text { Severe sepsis compared with } \\
\text { non-severe }\end{array}$ & 1.56 & $1.51-1.60$ \\
\hline $\begin{array}{l}\text { Sepsis occurring after } \\
\text { admission compared with sepsis } \\
\text { pre-admission }\end{array}$ & & \\
\hline
\end{tabular}

$\mathrm{Cl}=$ confidence interval.

*For patients admitted to acute hospitals outside of Quebec between April 2004 and March 2009

Source: Discharge Abstract Database, Canadian Institute for Health Information. patients for whom sepsis was not identified in the $\mathrm{ED}$ (odds ratio $[\mathrm{OR}]=0.88,95 \%$ confidence interval [CI] 0.80-0.97).

There are several potential reasons for this finding. First, patients for whom sepsis was diagnosed in the ED were perhaps more promptly admitted - either to the hospital wards or to the ICU - because appropriate triage and disposition are key components of the sepsis treatment protocol (Nguyen et al. 2006). For example, an average length of stay in the ED for patients for whom sepsis was diagnosed in the ED was 5.6 hours, compared with 6.4 hours for patients for whom sepsis was not diagnosed. Furthermore, for patients admitted to an ICU directly who had sepsis on the ED chart, the ED length of stay was also shorter (5.0 hours compared with 5.4 hours for patients without sepsis on the ED chart).

Second, more patients for whom sepsis was diagnosed in the ED were admitted to the ICU directly: $29.2 \%$ versus $17.3 \%$ of patients for whom sepsis was not diagnosed (OR 2.02, 95\% CI 1.82-2.24, after adjusting for age, sex and Charlson Index Score). Among patients admitted directly to an ICU, those for whom sepsis was recognized in the ED also experienced lower mortality (crude rates 33.8\% versus 43.5\%; OR 0.66, 95\% CI 0.54-0.80).

Third, although administrative data do not capture the time between assessment and treatment, it is likely that if sepsis were recognized in the ED, then the appropriate management and treatment would start earlier (Nguyen et al. 2006). Implementation of the 2004 Surviving Sepsis Campaign guidelines have led hospitals to develop standardized ED protocols to prevent ICU admissions, if possible, and to improve outcomes of patients with sepsis in the ICU (Canadian Institute for Health Information 2009). Thus, subject to the accuracy of sepsis documentation in the ED, this study confirms that timely recognition and appropriate management of sepsis in the ED lead to improved patient outcomes. enced lower crude mortality than did patients for whom sepsis was not identified (29.1\% versus $32.8 \%$, respectively). A logistic regression model was applied to estimate whether the presence of sepsis in the ED chart was a significant predictor of a lower mortality rate, after adjusting for the effects of sex, age and the Charlson Index score. After adjustment, patients for whom sepsis was identified in the ED had lower odds of dying compared with

\section{Limitations}

This study is subject to the limitations of the administrative database. First, the use of ICD-10-CA codes to identify sepsis cases is subject to the accuracy of documentation and coding. However, the codes selected to identify sepsis and severe sepsis in our study were used previously in the other sepsis studies that included administrative data (Angus et al. 2001; Dombrovskiy 
Table 4. Median and mean total LOSs, 2008-2009

\begin{tabular}{|c|l|}
\hline & Median LOS, Days (Mean) \\
\hline $\begin{array}{l}\text { All hospitalizations } \\
\text { (excluding sepsis) }\end{array}$ & $3(6.80)$ \\
\hline All sepsis & $12(25.9)$ \\
\hline Severe sepsis & $20(37.6)$ \\
\hline Non-severe sepsis & $9(18.3)$ \\
\hline
\end{tabular}

LOS = length of stay.

Source: Discharge Abstract Database, Canadian Institute for Health Information.

Table 5. ICU care, 2008-2009

\begin{tabular}{|c|l|l|}
\hline & $\begin{array}{l}\text { Percent Staying } \\
\text { in the ICU }\end{array}$ & $\begin{array}{l}\text { Median ICU LOS, } \\
\text { Days (Mean) }\end{array}$ \\
\hline $\begin{array}{l}\text { All hospitalizations } \\
\text { (excluding sepsis) }\end{array}$ & 8.5 & $2.3(4.7)$ \\
\hline All sepsis & 45.1 & $6.3(14.2)$ \\
\hline Severe sepsis & 72.4 & $9.5(18.2)$ \\
\hline $\begin{array}{c}\text { Non-severe } \\
\text { sepsis }\end{array}$ & 27.4 & $3.5(7.5)$ \\
\hline
\end{tabular}

ICU = intensive care unit; LOS = length of stay

Source: Discharge Abstract Database, Canadian Institute for Health Information.

et al. 2007; Martin et al. 2003). Martin et al. (2003) found, in the validation study, that using the codes from administrative databases to define sepsis resulted in acceptable predictive values. In addition, the distribution of the codes in our study did not substantially change over the study period (see Appendix 1, Table A1). Second, the DAD lacks data regarding the time of onset of specific conditions. Therefore, we could not determine whether the organ dysfunctions used to define severe sepsis occurred before or after an episode of sepsis. Despite these limitations, this study has the important advantage of being able to capture sepsis hospitalizations at the national level using a consistent approach.

\section{Conclusion}

Sepsis is an important contributor to in-hospital mortality and morbidity in Canada. Heightening the general awareness and understanding of national sepsis hospitalization and mortality rates is a key starting point. Sepsis care is clearly an important area for quality improvement efforts.

Lowering the numbers of those succumbing to this medical
Table 6. Top 10 conditions recorded as main problems

\begin{tabular}{|l|l|}
\hline Main Problem & Number $\left(\%^{*}\right)$ \\
\hline Other disorders of urinary system & $782(10.4)$ \\
\hline Pneumonia, organism unspecified & $780(10.4)$ \\
\hline Fever of other and unknown origin & $510(6.8)$ \\
\hline Abdominal and pelvic pain & $230(3.1)$ \\
\hline Cellulitis & $171(2.3)$ \\
\hline $\begin{array}{l}\text { Other symptoms and signs } \\
\text { involving cognitive functions and } \\
\text { awareness }\end{array}$ & $152(2.0)$ \\
\hline Heart failure & $145(1.9)$ \\
\hline Malaise and fatigue & $142(1.9)$ \\
\hline $\begin{array}{l}\text { Other non-infective gastroenteritis } \\
\text { and colitis }\end{array}$ & $137(1.8)$ \\
\hline Acute renal failure & $135(1.8)$ \\
\hline All other diagnoses & $4,301(57.5)$ \\
\hline
\end{tabular}

*Percentage of total number of patients in sepsis cohort without sepsis on emergency department chart.

Source: National Ambulatory Care Reporting System, Canadian Institute for Health Information.

condition can be a challenge as sepsis is difficult to diagnose and treat. But with early recognition of the signs and symptoms of sepsis, together with a more consistent implementation of care guidelines, the high mortality associated with sepsis can be reduced and lives can be saved. HQ

\section{Appendix 1: Algorithms Used To Identify Patients with Sepsis and Severe Sepsis in the DAD}

Patients with sepsis were identified in the DAD by using the ICD-10-CA codes presented in Table A1. The codes were selected based on the previous studies (Martin et al. 2003; Dombrovskiy et al. 2007), with input from classification specialists. The equivalent International Classification of Diseases, Ninth Revision, Clinical Modification (ICD-9-CM) codes were previously validated by Martin et al. (2003). The distribution of the codes was stable over the study period (see Table A1). Diagnosis types $\mathrm{M}, 1,2$, W, X or Y were used. Diagnosis type 3 (excluding cases where sepsis was one of the P.- codes) was only used if the following diagnoses were present on the same abstract as types M, 1, 2, W, X or Y: T80.2, T81.4, T88.0, 
Table A1. ICD-10-CA codes used to identify patients with sepsis in the Discharge Abstract Database

\begin{tabular}{|c|c|c|c|c|c|c|}
\hline \multirow{2}{*}{$\begin{array}{l}\text { ICD-10-CA } \\
\text { Codes* }\end{array}$} & \multirow[b]{2}{*}{ Description } & \multicolumn{5}{|c|}{ Percentage of Codes among Sepsis Cases } \\
\hline & & 2004-2005 & 2005-2006 & 2006-2007 & 2007-2008 & 2008-2009 \\
\hline A03.9 & Shigellosis, unspecified & 0.05 & 0.07 & 0.04 & 0.07 & 0.08 \\
\hline A02.1 & Salmonella septicaemia & 0.23 & 0.31 & 0.27 & 0.23 & 0.28 \\
\hline A28.0 & Pasteurellosis & 0.06 & 0.08 & 0.07 & 0.04 & 0.05 \\
\hline A32.7 & Listerial septicaemia & 0.09 & 0.10 & 0.11 & 0.07 & 0.22 \\
\hline A39.2 & Acute meningococcaemia & 0.08 & 0.10 & 0.04 & 0.07 & 0.08 \\
\hline A39.4 & Meningococcaemia, unspecified & 0.12 & 0.08 & 0.08 & 0.06 & 0.06 \\
\hline A40 & Streptococcal septicaemia & 7.62 & 8.18 & 8.33 & 8.37 & 8.39 \\
\hline A41.0 & Septicaemia due to Staphylococcus aureus & 9.07 & 9.08 & 8.95 & 9.13 & 9.05 \\
\hline A41.1 & Septicaemia due to other specified staphylococcus & 5.41 & 5.28 & 4.64 & 4.54 & 4.31 \\
\hline A41.2 & Septicaemia due to unspecified staphylococcus & 0.97 & 0.87 & 0.79 & 0.83 & 0.72 \\
\hline A41.3 & Septicaemia due to Haemophilus influenzae & 0.31 & 0.36 & 0.32 & 0.31 & 0.30 \\
\hline A41.4 & Septicaemia due to anaerobes & 0.55 & 0.47 & 0.44 & 0.50 & 0.49 \\
\hline A41.50 & Septicaemia due to Escherichia coli & 9.99 & 10.56 & 10.16 & 10.52 & 10.84 \\
\hline A41.51 & Septicaemia due to Pseudomonas & 1.68 & 1.89 & 1.92 & 1.66 & 1.85 \\
\hline A41.52 & Septicaemia due to Serratia & 0.34 & 0.41 & 0.30 & 0.26 & 0.28 \\
\hline A41.58 & Septicaemia due to other gram-negative organisms & 3.87 & 3.99 & 3.94 & 3.88 & 3.82 \\
\hline A41.80 & Septicaemia due to Enterococcus & 2.70 & 2.65 & 2.50 & 2.53 & 2.78 \\
\hline A41.88 & Other specified septicaemia & 4.56 & 4.64 & 4.48 & 4.26 & 4.26 \\
\hline A41.9 & Septicaemia, unspecified & 40.64 & 40.26 & 42.17 & 42.93 & 43.36 \\
\hline B00.7 & Disseminated herpesviral disease & 0.05 & 0.04 & 0.04 & 0.07 & 0.03 \\
\hline B37.7 & Candidal septicaemia & 1.18 & 1.15 & 1.12 & 1.06 & 1.11 \\
\hline P36 & Bacterial sepsis of newborn & 9.63 & 8.68 & 8.45 & 7.97 & 6.92 \\
\hline P35.2 & Congenital herpesviral [herpes simplex] infection & 0.08 & 0.08 & 0.09 & 0.07 & 0.12 \\
\hline P37.5 & Neonatal candidiasis & 0.7 & 0.6 & 0.66 & 0.52 & 0.55 \\
\hline
\end{tabular}

ICD-10-CA = International Statistical Classification of Diseases and Related Health Problems, 10th Revision, Canada

*0ther ICD-10-CA codes that were included (A21.7, A22.7, A23.9, A24.1, A26.7, A28.2, A39.3, A42.7, P37.2) had less than five cases in a year and are therefore not presented. These cases comprised $<0.1 \%$ of all sepsis cases.

Source: Discharge Abstract Database, Canadian Institute for Health Information.

T82.6, T82.7, T83.5, T83.6, T84.5, T84.6, T84.7, T85.7, O03.0, O03.5, O04.0, O04.5, O05.0, O05.5, O07.3, O08.0, O75.3, O85.-, O98.2, O98.5 and O98.8; and type 9: Y60.- to Y89.-. In the analysis of NACRS data, patients were considered to have sepsis if the diagnosis codes in the Table A1 were coded as "main" or "other problems."

Severe sepsis (including septic shock) was defined as sepsis complicated by organ dysfunction in at least one of the six organ systems (Table A2). The codes were selected based on the previous studies (Angus et al. 2001; Dombrovskiy et al. 2007; Martin et al. 2003) and input from classification specialists. The ICD-10-CA codes, typed as M, 1, 2, W, X and Y, and CCI (with extent attribute $=$ "EX") codes presented in Table A2 were used.

\section{References}

Angus, D.C., W.T. Linde-Zwirble, J. Lidicker, G. Clermont, J. Carcillo and M.R. Pinsky. 2001. "Epidemiology of Severe Sepsis in the United States: Analysis of Incidence, Outcome, and Associated Costs of Care." Critical Care Medicine 29(7): 1303-10.
Canadian Institute for Health Information. 2009. In Focus: A National Look at Sepsis. Ottawa, ON: Author. Retrieved December 16, 2009. <http://secure.cihi.ca/cihiweb/products/HSMR_Sepsis2009_e.pdf>.

Dombrovskiy, V.Y., A.A. Martin, J. Sunderram and H.L. Paz. 2007. "Rapid Increase in Hospitalization and Mortality Rates for Severe Sepsis in the United States: A Trend Analysis from 1993 to 2003." Critical Care Medicine 35(5): 1244-50.

Levy, M.M., M.P. Fink, J.C. Marshall, E. Abraham, D. Angus, D. Cook et al. 2003. "2001 SCCM/ESICM/ACCP/ATS/SIS International Sepsis Definitions Conference.” Intensive Care Medicine 29: 530-38.

Levy, M.M., R.P. Dellinger, S.R. Townsend, W.T. Linde-Zwirble, J.C. Marshall, J. Bion et al. 2010. "The Surviving Sepsis Campaign: Results of an International Guideline-Based Performance Improvement Program Targeting Severe Sepsis." Critical Care Medicine 38(2): 367-74.

Martin, C.M., F. Priestap, H. Fisher, R. Fowler, D.K. Heyland, S.P. Keenan et al. 2009. "A Prospective, Observational Registry of Patients with Severe Sepsis: The Canadian Sepsis Treatment and Response Registry." Critical Care Medicine 37(1): 81-88.

Martin, G.S., D.M. Mannino, S. Eaton and M. Moss. 2003. "The Epidemiology of Sepsis in the United States from 1979 through 2000." New England Journal of Medicine 348: 1546-54. 
Table A2. ICD-10-CA and CCI codes used to identify patients with severe sepsis in the Discharge Abstract Database

\begin{tabular}{|c|c|c|}
\hline System & ICD-10-CA and CCI Codes & Description \\
\hline Respiratory & $\begin{array}{l}\text { J96.0 } \\
\text { J96.9 } \\
\text { J80 } \\
\text { R09.2 } \\
\text { 1.GZ.31.CA-ND, 1.GZ.31.CR-ND, 1.GZ.31. } \\
\text { GP-ND }\end{array}$ & $\begin{array}{l}\text { Acute respiratory failure } \\
\text { Respiratory failure, unspecified } \\
\text { Adult respiratory distress syndrome } \\
\text { Respiratory arrest } \\
\text { Mechanical ventilation }\end{array}$ \\
\hline Cardiovascular & $\begin{array}{l}\text { R57 } \\
195.1 \\
195.8 \\
195.9\end{array}$ & $\begin{array}{l}\text { Shock } \\
\text { Orthostatic hypotension } \\
\text { Other hypotension } \\
\text { Hypotension, unspecified }\end{array}$ \\
\hline Renal & N17 & Acute renal failure \\
\hline Hepatic & $\begin{array}{l}\mathrm{K} 72.0 \\
\mathrm{~K} 72.9 \\
\mathrm{~K} 76.3\end{array}$ & $\begin{array}{l}\text { Acute and subacute hepatic failure } \\
\text { Hepatic failure, unspecified } \\
\text { Infarction of liver }\end{array}$ \\
\hline Neurological & $\begin{array}{l}\text { F05.0 } \\
\text { F05.9 } \\
\text { G93.1 } \\
\text { G93.4 } \\
\text { G93.80 }\end{array}$ & $\begin{array}{l}\text { Delirium not superimposed on dementia } \\
\text { Delirium, unspecified } \\
\text { Anoxic brain damage } \\
\text { Encephalopathy, unspecified } \\
\text { Metabolic encephalopathy }\end{array}$ \\
\hline Hematological & $\begin{array}{l}\text { D69.5 } \\
\text { D69.6 } \\
\text { D65 }\end{array}$ & $\begin{array}{l}\text { Secondary thrombocytopenia } \\
\text { Thrombocytopenia, unspecified } \\
\text { Disseminated intravascular coagulation }\end{array}$ \\
\hline
\end{tabular}

CCI = Canadian Classification of Health Interventions; ICD-10-CA = International Statistical Classification of Diseases and Related Health Problems, 10th Revision, Canada.

Members of the American College of Chest Physicians/Society of Critical Care Medicine Consensus Conference Committee. 1992. "Definitions for Sepsis and Organ Failure and Guidelines for the Use of Innovative Therapies in Sepsis." Critical Care Medicine 20: 864-74.

Nguyen H.B., E.P. Rivers, F.M. Abrahamian, G.J. Moran, E. Abraham, S. Trzeciak et al. 2006. "Severe Sepsis and Septic Shock: Review of the Literature and Emergency Department Management Guidelines." Annals of Emergency Medicine 48(1): 28-54.

Quan, H., V. Sundararajan, P. Halfon, A. Fong, B. Burnand, J.C. Luthi et al. 2005. "Coding Algorithms for Defining Comorbidities in ICD-9-CM and ICD-10 Administrative Data." Medical Care 43(11): 1130-39.

Surviving Sepsis Campaign. 2008. Background. Retrieved October 30, 2009. <http://www.survivingsepsis.org/Background/Pages/default. aspx>.

\section{About the Authors}

Liudmila Husak, MD, MPH, is a project lead in the Health Indicators team at the Canadian Institute for Health Information (ClHI), Toronto, Ontario. Previously, she worked as a health outcomes researcher in the United States and the Ukraine.
Annette Marcuzzi, BScPT, MHSc, CHE, is currently working at $\mathrm{CIHI}$ (Toronto) as a project lead in the Health Indicators team. Prior to joining $\mathrm{CIHI}$ she held various leadership positions at St. John's Rehab and the University Health Network. Annette is a lecturer in the Department of Physical Therapy, University of Toronto.

Jeremy Herring, MSc, is a project lead in the Primary Healthcare Information team at $\mathrm{CIHI}$ (Toronto). Previously, he was a senior analyst in the $\mathrm{CIHI}$ Health Indicators team.

Eugene Wen, MD, DrPH, manager of health indicators at $\mathrm{CIHI}$ (Toronto), has been with $\mathrm{ClHI}$ since 2000. His work is focused on developing new national health indicators, producing comparative indicator reports and knowledge transfer on applying health indicators in the field.

Ling Yin, MD, MSc, MPH, is a senior analyst for the Health Indicators team at $\mathrm{ClHI}$ (Toronto).

Dragos Daniel Capan, MStat, BSApMath, is a senior analyst for the Health Indicators team at $\mathrm{ClHI}$ (Toronto).

Geta Cernat, MD, is currently a family medicine resident at Queen's University, ON. Previously, she worked as a senior analyst in the Health Indicators team at $\mathrm{CIHI}$ (Toronto). 